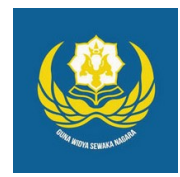

Jurnal Analogi Hukum

Journal Homepage: https://ejournal.warmadewa.ac.id/index.php/analogihukum

\title{
Hak Wanita Tunggal terhadap Warisan dalam Hukum Adat Bali
}

\author{
I Putu Andre Warsita*, I Made Suwitra dan I Ketut Sukadana
}

Fakultas Hukum, Universitas Warmadewa, Denpasar, Bali-Indonesia

*andrewarsita@gmail.com

\begin{abstract}
How To Cite:
Warsita, I. P. A., Suwitra, I. M., \&., Sukadana, I. K. (2020). Hak Wanita Tunggal terhadap Warisan dalam Hukum Adat Bali. Analogi Hukum. 2(1). 83-87. Doi: http://dx.doi.org/10.22225/.2.1.1628.83-87

Abstract-Inheritance customary law is a customary law that regulates how inheritance or inheritance is forwarded or divided from heirs to inheritors from generation to generation. Balinese indigenous people with the patrilineal family system, cause only descendants of kapurusa status are considered to be able to take care and carry on family responsibilities. The formulation of the problem in this study is how inheritance rights for women in Balinese customary law, what is the procedure for granting inheritance rights for single women to family inheritance. This research is a normative legal research. The problem approach used is the case approach, conceptual and legislative approach. Legal material used by primary and secondary legal materials. The results of the study and discussion show that inheritance rights for women in Balinese customary law are essentially women who are not heirs according to the Bali Customary Law, but women are entitled to a share of inheritance from their parents, which in practice is used with various terms including property and, provision of life, the soul of the soul and also called the soul of the fund. The procedure for granting inheritance rights for a single woman to the family's inheritance of a Single Female child can be an heir by changing the status, from predana status to purusa status.
\end{abstract}

Keywords: Single Woman, Inheritance, Balinese Customary Law

\begin{abstract}
Abstrak-Hukum adat waris adalah aturan hukum adat yang mengatur tentang bagaimana harta peninggalan atau harta warisan diteruskan atau dibagi dari pewaris kepada para waris dari generasi ke generasi. Masyarakat adat Bali dengan sistem kekeluargaan patrilineal, menyebabkan hanya keturunan yang berstatus kapurusa dianggap dapat mengurus dan meneruskan tanggung jawab keluarga. Rumusan masalah dalam penelitian ini adalah bagaimanakah hak waris bagi wanita dalam hukum adat Bali, Bagaimana prosedur pemberian hak waris bagi wanita tunggal terhadap harta warisan keluarga. Penelitian ini adalah penelitian hukum normatif. Pendekatan masalah yang digunakan adalah pendekatan kasus,konseptual dan pendekatan perundangundangan. Bahan hukum yang digunakan bahan hukum primer dan sekunder. Hasil penelitian dan pembahasan menunjukkan bahwa Hak waris bagi wanita dalam hukum adat Bali pada dasarnya Wanita bukan ahli waris menurut Hukum Adat Waris Bali, namun wanita berhak mendapat bagian harta warisan dari orang tuanya, dimana dalam praktek pemberian tersebut dipergunakan dengan berbagai macam istilah diantaranya harta tetatadan, bekal hidup, pengupa jiwa dan juga disebut jiwa dana.Prosedur pemberian hak waris bagi wanita tunggal terhadap harta waris keluarga anak Wanita Tunggal bisa menjadi ahli waris dengan jalan perubahan status yaitu dari status predana menjadi status purusa.
\end{abstract}

Kata Kunci: Wanita Tunggal, Pewarisan, Hukum Adat Bali

\section{Pendahuluan}

Dalam sistem kewarisan di Bali dikenal 3 sistem, yaitu: "Kewarisan Individual, Kewarisan Kolektif dan Kewarisan Mayorat, yang disana-sini disertai dengan variasi sesuai dengan kala patra." (Sutha, 1982) bahwa hukum adat waris di Bali masih beragam sifatnya, dalam arti kewarisan disatu desa adat tertentu belum tentu sama dengan kewarisan di desa adat lainnya.

Dengan dianutnya sistem kebapakan (patrilineal) di Bali, maka yang menonjol adalah anak laki-laki. Anak laki-laki akan meneruskan keluarga itu, sedangkan anak wanita tidak demikian adanya. Karena sesuai dengan sistem kekeluargaan patrilineal (di Bali) 
anak wanitaakan keluar dari keluarganya dengan diadakannya perkawinan.

Soepomo mengatakan Hukum adat waris memuat peraturan-peraturan yang mengatur tentang proses meneruskan serta mengoperkan barang-barang harta benda dan barang-barang yang tidak berwujud benda (immaterial goederen) dari suatu angkatan manusia (generatie) kepada keturunannya. Prosesproses itu tidak menjadi akut oleh sebab orang tua meninggal dunia. Memang meninggalnya Bapak atau Ibu adalah suatu peristiwa yang penting dalam proses itu, akan tetapi tidak mempengaruhi secara radikal proses penerusan dan pengoperan harta benda tersebut (Soepomo, 2000).

Dari uraian tersebut di atas, menunjukkan bahwa penerusan harta warisan tidak harus dilakukan setelah pewaris meninggal dunia. Di Bali pada umumnya, harta warisan baru beralih setelah pewaris meninggal dunia, dan mengenai pembagiannya dilakukan setelah almarhum pewaris diabenkan.

Putusan pengadilan Tinggi Denpasar tanggal 31 Maret 1970 No.13/PTD/1967/Pdt, yang dikuatkan oleh Keputusan Mahkamah Agung tanggal 10 April 1971 No. 770/K/ Sip/1970, yang pada pokoknya mengatakan bahwa harta peninggalan seorang suami masih belum dapat dibagi ahli warisnya selama almarhum belum diabenkan. Mengenai hal tersebut menurut V.E. Korn dalam bukunya Hukum Adat Waris di Bali mengatakan: "Tidak benar menurut paswara hukum waris pembagian harta warisan seseorang yang telah meninggal dunia baru boleh dilakukan setelah diselenggarakannya pengabenan (Beni \& Sagung, 1986).

Selanjutnya dikatakan dalam praktik kehidupan masyarakat desa di Bali hal yang dituangkan dalam Putusan Pengadilan Tinggi Denpasar di atas tidak bersifat mutlak, melainkan terserah kepada ahli waris.Dengan demikian mungkin saja pembagian warisan dilakukan semasih hidupnya pewaris. Hal ini menurut penulis ada baiknya, karena apabila pembagian dilakukan semasih pewaris hidup, maka peristiwa-peristiwa sehubungan dengan pembagian tersebut diketahuinya, sehingga pewaris dapat memberikan petuah-petuah serta saran-saran bila terjadi perselisihan antara para ahli waris. Bahkan pewaris dapat melihat langsung tentang sifat dan watak para ahli waris, karena ahli waris yang tidak memperhatikan pewaris, maka hak warisnya dapat ditolak oleh pewaris. Karena pada intinya pewarisan itu merupakan pengoperan serta penerusan hak dan kewajiban pada generasi berikutnya.

Masyarakat adat Bali ditemukan suatu keluarga mempunyai seorang anak wanita, dalam penerapan pewarisanya wanita tidak berhak menerima harta warisan dari kedua orang tuanya, sebagaimana diketahui bahwa di Bali menganut sistem patrilineal dalam garis keturunanya yang mengharuskan sebuah keluarga memiliki anak laki-laki untuk melanjutkan keturunannya dan menjadi pewaris keluarga tersebut baik secara niskala maupun sekala. Hal tersebut berarti akan membuat keluarga yang tidak memiliki anak laki-laki tidak akan memiliki pewaris untuk melanjutkan garis keturunannya, namun pada kenyataan sekarang ini masih sedikit masyarakat Bali yang hanya memiliki anak wanita tunggal tetap dapat melanjutkan garis keturunannya atau dengan kata lain tetap dapat mewaris.

Berdasarkan latar belakang tersebut diatas, maka dapat dirumuskan analisis dalam penelitian ini terbatas pada hak waris bagi wanita dalam hukum adat Bali dan prosedur pemberian hak waris bagi wanita tunggal terhadap harta waris keluarga.

\section{Metode}

Tipe Penelitian ini menggunakan jenis penelitian hukum normatif. Penelitian ini membahas mengenai kekaburan norma dalam awig-awig Desa Adat Bedaulu tentang warisan dan hak wanita tunggal terhadap warisan. Pendekatan yang digunakan didalam penelitian adalah pendekatan kasus (cese approach), pendekatan konseptual (conceptual approach) dan pendekatan perundang-undangan (statue approach). Sumber bahan hukum merupakan subjek dari mana bahan hukum di peroleh, diambil, dan dikumpulkan. Analisis bahan hukum adalah pengolahan bahan hukum yang diperoleh dari penelitian pustaka. Adapun teknik pengolahan dan analisis hukum di dalam penulisan ini, akan dilakukan dengan cara deskriptif analisis dan menyusaikan dengan argumentasi hukum

\section{Hasil dan Pembahasan}

\section{Hak Waris Bagi Wanita dalam Hukum Adat Bali}

Dalam kenyataan tidak jarang ditemukan sengketa dalam pengangkatan anak.Dari uraian tersebut diatas pada prinsipnya setiap orang yang sudah kawin boleh mengangkat anak seperti apa yang dikatakan oleh B. Bastian Tafal: "Pada prinsipnya setiap orang yang 
sudah kawin tetapi tidak memperoleh anak dapat mengangkat anak kecuali orang yang kawin kaceburin. Demikian pula bunyi keputusan Pengadilan Tinggi Denpasar pada tanggal 28 Oktober 1966 No.76/PT.1966/Pdt. Bila suami yang hendak mengangkat anak maka akan meminta persetujuan istrinya terlebih dahulu demikian pula sebaliknya isteri yang mengangkat anak harus dengan persetujuan suaminya.

Oleh karena sistem kekeluargaan di Bali patrilineal, maka akan menjadi masalah bagi keluarga yang hanya mempunyai anak wanita tanpa anak laki-laki. Hukum adat Bali memberikan upaya terhadap masalah ini yaitu: dengan adanya perubahan status anak wanita menjadi anak laki-laki. Sehingga mempunyai status atau kedudukan sebagai sentanarajeg (anak laki-laki). Perubahan status ini disebut dengan sentanarajeg selanjutnya perkawinannya disebut kawin kaceburin.

\section{Prosedur Pemberian Hak Waris Bagi Wanita Tunggal Terhadap Harta Waris Keluarga}

Seperti apa yang dikatakan oleh I Gede Wayan Pangkat: Jika anak wanita tunggal itu ditetapkan menjadi anak sentana orang tuanya (sentanaluh, sentanarajeg) maka suami yang melakukan perkawinan nyeburin padanya sering kali didalam hak tertentu, menempati tempat kedua dibandingkan kedudukan isterinya. Tetapi lain halnya dengan anak-anak yang lahir dari perkawinan nyeburin itu, bahwa anak-anak itu berhak penuh atas harta ibunya misalnya bila terjadi perceraian, maka si suami sama sekali tidak memperoleh bagian anak ataupun hanya sebagian saja. Si suami yang demikian itu kurang lebih berkedudukan dalam hal-hal sebagai seorang wanita.

hal itu sesuai Awig-Awig Desa Adat Bedaulu, Pawos 79 sampai Pawos 82 berbunyi :

\section{Pawos 79}

a. Mungguwing sentana wenten kaucap :

b. Prade sadurung pawidi widana sampun ngewentenang sentana mangda tan kantun kaucap astra utawi babijat patut kemanggala antuk upacara pemerascita.

c. Prade pawiwahane tan ngewetuang Santana kengin ngidih sentana antuk upasaksi sekala niskala sane kewasatanin sentana peperasan.

d. Prade wenten sinalih tunggil krama madruwe putra kembar, lanang istri utawi sebaliknyane, desa patut ngawentenan pecaruan ring desa olih krama desa muah ring paumahan olih sang madruwe oka.

Pawos 80

a. Ngangkat sentana manut dudonan, macihna arta brana pamerasan kesaksiang sekala niskala, maduluran ilakita pamerasan sentana.

b. Sapa sira ugi paoang ngangkat sentana patut mesadok ring prajuru.

c. Bendesa patut nyiarang ring sawidangan desane, sang rumasa tan lila mangda nyadokang.

d. Bendesa digelis mawosin.

Pawos 81

a. Pamerasan sinaggeh kapatut ring Bedaulu risampun makaoihna :

- Widi-widana pamerasan.

- Kesaksinin antuk prajuru desa, lan usaha kesiarang ring paruman.

- Wenten ilikita unggahan tata salur pemargin pamerasan.

b. Sane patut keperas anggen sentana kadi ring sor:

- Jatma sane meagama Hindhu (ritatkala pemerasan).

- Kengin ngangkat sentana langkungan ring adiri (lanang wadon).

Pawos 82

a. Wrisan inggih punika tetamian artha berana saha ayah-ayahan ngupadi sukerta sekala niskala, saking keluhuranyane arep ring turunannyane.

b. Sane kaucap warisan luire :

- Duwe tengah, karang paumahan, merajan.

- Pagunakayaan, tetatadan, jiwa dana, utang piutang.

a. Wawu kengin kebawos warisan prade:

- Wenten sang mapiturun utawi pewaris.

- Wenten turunanyane utawi akhli waris.

- Wenten arta berana miwah tetegenang/ ayah-ayahan marupa warisan. 


Mengenai sentanarajeg tidak perlu
pengesahan seperti widi widana seperti pengangkatan seorang anak. Yang penting dalam sentanarajeg adalah apabila seorang wanita terus dikawin kaceburindalam arti pihak suaminya masuk keluarganya. Dengan peristiwa seperti ini sentanarajeg dinyatakan sah. Selanjutnyaakan mewarisi segala harta kekayaan yang ditinggalkan oleh orang tuanya. Dan kalau terjadi perceraian maka suaminya tidak mendapat bagian atas harta itu karena suami dalam perkawinan ini berstatus wanita.

Di lain pihak keputusan Pengadilan Tinggi Denpasar sudah merupakan yurisprudensi tanggal 22 Juli 1972 No.105/PTD/1972/Pdt menentukan seorang anak wanita memperoleh status hukum laki-laki apabila dijadikan sentanarajeg atau dikawin kaceburin.Dari putusan ini yang menjadi ahli waris adalah anak laki-laki dan anak wanita yang beralih status menjadi laki-laki atau sentanarajeg. Dari keputusan ini ternyata sedikit membuat kelonggaran akan hak anak wanita, setidaknya untuk mendapat bagian harta warisan orang tuanya.

Dalam hal keberadaan wanita seakan-akan mengundang pertanyaan sudah sesuaikan dengan keadilan masyarakat Bali jika anak wanita digariskan kedudukannya seperti tersebut diatas. Mengenai masalah ini kiranya perlu dikemukakan komentar dari I Ketut Artadi:

Keadaan ini (janda tidak mewaris) menurut hemat kami tidak dapat dipertahankan mengingat perubahan-perubahan atau perkembangan-perkembangan masyarakat Bali, dimana antara lain kedudukan pria dan wanita dalam semua bidang adalah sama dan lain-lain hal lagi. Maka sebab itu anak wanita dan janda harus diberikan hak dan warisan yang harus diterimanya dimanapun (sesudah kawin keluar, cerai) dalam kedudukan apapun (dahatua, mulih daha) si anak wanita itu berada (Artadi, 1987).

Pandangan ini memperlihatkan gambaran pada sistim kekeluargaan yang bilateral atau parental, karena yang dikehendaki adalah persaaan hak antara wanita dengan laki-laki, dalam segala hak serta kewajiban, termasuk didalamnya hak untuk mewaris harta kekayaan orang tuanya.Selanjutnya wanita mempunyai hak yang sama pula dalam waris mewaris menurut hukum adat (khususnya di Bali). Adapun kehilangan hak menikmati dari harta warisan itudapat terjadi apabila anak Wanita itu kawin keluar dan dipecat sebagai anak oleh orang tuanya (Windia, 2014).
Selain itu, adanya perubahan status bagi Wanita, maka bagi keluarga yang tidak mempunyai anak laki-laki tetap akan mempunyai ahli waris yang akan mewarisi harta kekayaannya. Karena dengan adanya perubahan status dari Wanita menjadi laki laki maka juga akan merubah hak dan kewajibannya di dalam keluarga yang bersangkutan. Wanita yang berubah status yang disebut dengan sentana rajeg maka akan mempunyai hak untuk mewaris. Hal ini telah menjadi Yurisprudensi, yaitu Putusan Pengadilan Tinggi Denpasar tanggal 19 Juli 1961 Nomor 81/Ptd/1976/Pdt, dan putusan Pengadilan Tinggi Denpasar tanggal 18 Agustus1970 Nomor 2/PTD//1979/ Pdt, yang berbunyi anak angkat (sentana) menurut Hukum Adat Bali adalah ahli waris dari orang tua angkatnya.

Dari putusan Pengadilan Tinggi tersebut dapatlah dikatakan bahwa sesungguhnya Anak Wanita Tunggal bisa menjadi ahli waris dengan jalan perubahan status yaitu dari status Wanita menjadi status laki-laki. Jadi agar anak Wanita Tunggal dapat menerima harta warisan sebagai pemberian nafkah hidup bahkan dapat menjadi ahli waris apabila anak Wanita Tunggal tersebut diberi status sebagai Sentana Rajeg dan memilih bentuk perkawinan kaceburin.

"Sebagai konsekuensi dianutnya sistem kekeluargaan Patrilinial maka peranan Wanita dalam hubungannya dengan harta warisan tidaklah begitu besar". Bahkan pendapat umum dimasyarakat hingga sekarang belum dapat memberikan hak untuk mewaris kepadaanak Wanita.

\section{Simpulan}

Berdasarkan uraian tersebut diatas dapatlah ditarik simpulan sebagai berikut: Hak waris bagi wanita dalam hukum adat Bali pada hakekatnya Wanita bukan ahli waris menurut Hukum Adat Waris Bali, namun wanita berhak mendapat bagian harta warisan dari orang tuanya, dimana dalam praktek pemberian tersebut dipergunakan dengan berbagai macam istilah diantaranya harta tetatadan, bekal hidup, pengupa jiwa dan juga disebut jiwa dana.

Prosedur pemberian hak waris bagi wanita tunggal terhadap harta waris keluarga anak Wanita Tunggal bisa menjadi ahli waris dengan jalan perubahan status yaitu dari status predana menjadi status purusa. Jadi agar anak Wanita Tunggal (predana) dapat menerima harta warisan sebagai pemberian nafkah hidup bahkan dapat menjadi ahli waris apabila anak Wanita Tunggal (predana) tersebut diberi status sebagai Sentana Rajeg dan memilih bentuk 
perkawinan kaceburin (nyentana).

Sesuai dengan kesimpulan tersebut diatas, dapat penulis sampaikan kepada Majelis Utama Desa Pakraman (MUDP) sebagai organisasi tertinggi umat Hindu agar memahami masalah waris ke waris sehingga dalam memberikan sosialisasi kepada masyarakat tidak/justru menimbulkan masalah.

Kepada masyarakat Bali pada umumnya agar dalam pewarisan (pembagian waris) menjunjung tinggi norma atau hukum adat yang berlaku sehingga tidak terjadi salah penafsiran terhadap pewarisan, agar tidak hanya karena harta warisan membuat perpecahan dalam keluarga.

\section{Daftar Pustaka}

Artadi, I. K. (1987). Hukum Adat Bali Dengan Aneka Masalah Dilengakpi Yurisprudensi (Cetakan II). Denpasar: Setia Kawan.

Beni, I. W., \& Sagung, N. (1986). Hukum Adat Di Dalam Yurisprudensi (Cetakan II). Denpasar: Surya Jaya.

Soepomo. (2000). Bab-Bab Tentang Hukum Adat (Cetakan IV). Jakarta: Pradnya Paramitha.

Sutha, I. G. K. (1982). Beberapa Aspek Hukum Waris Bali. Majalah Kertha Patrika, 24.

Windia, W. P. (2014). Hak Waris Perempuan Menurut Hukum Adat Bali. Denpasar: Artikel Ilmiah Fakultas Hukum Universitas Udayana. 